水 文 · 水資 源学 会誌

J. Japan Soc. Hydrol. \& Water Resour.

Vol. 16, No. 6(2003) pp. 589-594

\title{
Hargreaves 式に基づく月平均蒸発計蒸発量の推定
}

\author{
Estimation of Mean Monthly Pan Evaporation Based on Hargreaves Equation
}

\author{
松井宏之* （宇都宮大学農学部) \\ MATSUI Hiroyuki Faculty of Agriculture, Utsunomiya University
}

\begin{abstract}
The Hargreaves equation can calculate monthly mean evaporation/evapotranspiration using only air temperature with two coefficients. First, it is confirmed that the Hargreaves equation with general coefficients gives better pan evaporation estimates than estimated results for pan evaporation from 143 meteorological stations in Japan and results generated using the Thornthwaite and the Hamon equations. In a further attempt to improve accuracy, two equations are determined to estimate the values of the two coefficients that can be applied throughout Japan with the exception of the Nansei Islands in the subtropical southwest of Japan. It is shown that the Hargreaves equation plus the two new equations gives an improved estimation accuracy with a root mean square error of $0.65 \mathrm{~mm} \pm 0.26 \mathrm{~mm}$ (Ave. \pm S.D.).
\end{abstract}

Key words: Pan evaporation, Hargreaves equation, Long-term variation, Climatic variation

気温のみを入力として月平均蒸発量 (月平均蒸発散量) を推定できるハーグリーヴス式 ( $\mathrm{Hr}$ 式) に着目し，全国 143 地点におけ る小型蒸発計蒸発量の推定を行った . 兴の結果, 同じく温度のみを入力とするソーンスウェイト式, ハモン式と比較して, $\mathrm{Hr}$ 式の 適合性が高いことを示した .さらに，精度の向上を图るため，Hr 式に含まれる 2 つの定数について検討し，南西諸島を除く日本全 国に適用できる定数の推定式を導いた .これらの推定式を用いることにより，Hr 式がRMSE $0.65 \mathrm{~mm} \pm 0.26 \mathrm{~mm}$ (平均標準偏差) の精度でわが国の月平均蒸発量を推定できることを示した 。

キーワード : 小型蒸発計蒸発量, ハーグリーヴス式, 長期変動, 気候変動

\section{I . はじめに}

地球温暖化に伴う気候変動が指摘されるなか, 将 来の水資源動向を探る上で, 降水量, 蒸発散量ある いは蒸発量の長期変動を把握しておくことはきわめ て重要である . 降水量は観測密度の違いこ关あるも のの，長年にわたり観測が継続されているため，長 期の変動傾向を把握することは比較的容易であり， 多くの報告事例がある . 一方, わが国における蒸発 量の観測地点は全国で14地点 (2002年時点) しかな い. 弚のため, ペンマン式により推定されることが 多いが, ペンマン式には気温, 湿度, 風速, 日射量 (あるいは日照率)のデータが必須であり, 推定可能 な地点・年数には限界がある .こうしたことから， 蒸発量の長期変動を探るには蓄積のあるデータを用
いた方法が必要とされる．また，山地流域で長期の 流出解析を行う際にも, 利用可能なデータが限られ ることから, 簡便で精度よく蒸発散量（あるいは蒸 発量) を推定できる方法が必要とされることがある． 乥こで, データの蓄積がある気温のみを入力とし て蒸発量を推定するハーグリーヴス式に着目し，(1) わが国への適合性およびその有効性，(2)弚の式中に 含まれる定数項の值，について検討した .

なお，本稿で用いるハーグリーヴス式，ソーンス ウェイト式, ハモン式は, いずれも蒸発散量の推定 式である．しかし, 検証データとして蒸発散量デー タが得られないことから, データが整備されている 小型蒸発計蒸発量の推定式として扱った . 小型蒸発 計蒸発量は, 気候, 植生, 土壤の条件により実際の 蒸発散量と同一ではないが, 参考値としては極めて

*宇都宮大学農学部 $7321-8505$ 栃木県宇都宮市峰町350

Faculty of Agriculture, Utsunomiya University, Mine-machi 350, Utsunomiya, Tochigi 321-8505, Japan 
有用である .

\section{II . ハーグリーヴス式の概要}

ハーグリーヴス式 (Hargreaves et al., 1982) は， ライシメータからの蒸発散量の推定を目的として提 案され,

$$
\begin{aligned}
E T_{o} & =\epsilon \cdot T F_{\text {mean }} \frac{R_{s}}{\lambda} \\
& =\epsilon \cdot T F_{\text {mean }} K_{T} \sqrt{T F_{\text {max }}-T F_{\min }} R_{a}
\end{aligned}
$$

$E T_{o}:$ ハーグリーヴス式による蒸発散量 $\left(\mathrm{mm} \cdot \mathrm{d}^{-1}\right)$,

$T F_{\text {mean }}$ : 月平均気温 $\left({ }^{\circ} \mathrm{F}\right)$,

$\epsilon$ : 経験定数 $\left(=0.0075^{\circ} \mathrm{F}^{-1}\right)$,

$R_{S}=k_{T} \sqrt{T F_{\text {max }}-T F_{\text {min }}} \cdot R_{a}$ : 全天日射量 $\left(\mathrm{MJ} \cdot \mathrm{m}^{-2} \cdot \mathrm{d}^{-1}\right)$,

$k_{T}$ : 地域定数 $\left({ }^{\circ} \mathrm{F}^{-0.5}\right)$,

$R_{a}:$ 大気外日射量 $\left(\mathrm{MJ} \cdot \mathrm{m}^{-2} \cdot \mathrm{d}^{-1}\right)$,

$T F_{\text {max }}, T F_{\text {min }}$ : 月平均最高 (最低) 気温 $\left({ }^{\circ} \mathrm{F}\right)$,

$\lambda$ : 蒸発潜熱 $\left(\mathrm{MJ} \cdot \mathrm{kg}^{-1}\right)(\approx 2.45)$

と表される。(2)式を捸氏に換算し((3)式)，換算後の 地域定数 $k 0_{R S}\left({ }^{\circ} \mathrm{C}-0.5\right)$ を0 17(内陸部では0 16, 臨 海部では0 19とされるが，一般的に0 17が用いられ る) としたのが，一般的なハーグリーヴス式 ((4)式; Hargreaves et al., 1985) である.

$$
\begin{aligned}
E T_{o} & =\epsilon \cdot\left(32+1.8 T_{\text {mean }}\right) k \mathrm{O}_{R s} \sqrt{T_{\max }-T_{\min }} \frac{R_{a}}{\lambda} \\
& =0.0023 \cdot\left(T_{\text {mean }}+17.8\right) \sqrt{T_{\max }-T_{\min } \frac{R_{a}}{\lambda}}
\end{aligned}
$$

$k 0_{R S}$ : 地域定数 $\left(=\sqrt{1.8} \cdot k_{T} ;{ }^{\circ} \mathrm{C}^{-0.5}\right)$,

$T_{\text {mean }}$ : 月平均気温 $\left(=0.5 \times\left(T_{\max }+T_{\min }\right) ;{ }^{\circ} \mathrm{C}\right)$,

$T_{\max }, T_{\min }$ : 月平均最高 (最低) 気温 $\left({ }^{\circ} \mathrm{C}\right.$ )

ハーグリーヴス式(以下 , $\mathrm{Hr}$ 式と表す)は気温, 全 天日射量の項からなるため, マッキンク式 (Makkink, 1957) , ジェンセン・ハイズ式 (Jensen et al., 1963) などと同じく, 放射温度法に分類される. $\mathrm{Hr}$ 式は日射以外の項を持たないことから，構成的には プリーストリー・ティラー式 (Priestley et al., 1972) に近い.

$\mathrm{Hr}$ 式の全天日射量は日較差を変数とする式によ り推定されるため, 放射温度法に分類される前出 2 式と比べて推定精度の低下は否めないが, 気温のみ を入力データとしていることから，適用時期・範囲 の拡大が見込める .

ここで, $\mathrm{Hr}$ 式 ((3)式) には経験定数 $€$ および地域 定数 $k 0_{R s}$ の $2 つ$ の゚ラメータが含まれる .これらに ついて，IIIで上述した一般的な値を用いて $\mathrm{Hr}$ 式 の推定精度を検討し，IVでは任意地点での值を一意
に定めることができるよう地理的条件，気温依存性 などを検討した .

\section{III . ハーグリーヴス式の適合性および有効性}

蒸発量の計算は, 1961年〜1965年の 5 年間にかけ て全国143地点の気象官署で観測された小型蒸発計 蒸発量を検証データとして行った。この際，地域定 数 $k 0_{R S}$ は既往の研究と同じく一律に0 17 , 経験定数 $\epsilon$ は0 .0075とした. そとて, 推定結果の評価関数に は相関係数 $r$, 平均 2 乗平方根誤差 RMSE (Root Mean Square Error，(5)式) を用いた .

$$
R M S E=\sqrt{\frac{1}{N} \sum\left(O b s_{i}-E s t_{i}\right)^{2}}
$$

$N:$ データ数,

$O b s_{i}: i$ 月の観測された月平均蒸発量 $\left(\mathrm{mm} \cdot \mathrm{d}^{-1}\right)$, $E s t_{i}: i$ 月の推定された月平均蒸発量 $\left(\mathrm{mm} \cdot \mathrm{d}^{-1}\right)$ また , Hr 式と同じく気温のみを入力とするソーン スウェイト式 ((6)式; 以下 Tw 式と表す)，八モン式 ((7)式 ; 以下 $\mathrm{Hm}$ 式と表す) の推定結果と比較する ことにより, 有効性の検証を試みた . 併せて, 蒸発 量の一般的な推定法である Penman 式 ((8)式) によ る推定値との比較も行った .

$$
\begin{aligned}
\text { ソーンスウェイト式 } \\
E_{T w}=0.533 \cdot D_{0}\left(10 T_{i} / J\right)^{a} \\
\left\{\begin{array}{l}
a=\left(492390+17920 J-771 J^{2}+0.675 J^{3}\right) \cdot 10^{-6} \\
J=\sum_{i=1}^{12}\left(T_{i} / 5\right)^{1.514}
\end{array}\right.
\end{aligned}
$$

$E_{T w}:$ ソーンスウェイト式による蒸発量 $\left(\mathrm{mm} \cdot \mathrm{d}^{-1}\right)$, $D_{0}: i$ 月の可照時間 $\left(12 \mathrm{~h} \cdot \mathrm{d}^{-1}\right.$ を 1 とする $)$,

$T_{i}:\left(\right.$ 一般的な) $i$ 月の月平均気温 $\left({ }^{\circ} \mathrm{C}\right)$

八モン式

$$
E_{H m}=014 \cdot D_{0}^{2} p,
$$

$E_{H m}$ : ハモン式による蒸発量 $\left(\mathrm{mm} \cdot \mathrm{d}^{-1}\right)$,

$p_{t}$ : 月平均気温 $T_{i}$ に対する飽和絶対湿度 $\left(\mathrm{g} \cdot \mathrm{m}^{-3}\right)$ ペンマン式

$$
E_{P e n}=\frac{\Delta}{\Delta+\mathrm{Y}}\left(\frac{R_{n}}{\lambda}\right)+\frac{\mathrm{Y}}{\Delta+\mathrm{Y}} f\left(u_{2}\right)\left(e_{s a}-e_{a}\right)
$$

$E_{P e n}$ : ペンマン式による蒸発量 $\left(\mathrm{mm} \cdot \mathrm{d}^{-1}\right)$,

$\Delta:$ 飽和水蒸気圧曲線の勾配 $\left(\mathrm{hPa} \cdot{ }^{\circ} \mathrm{C}^{-1}\right)$,

$\mathrm{Y}$ : 乾湿計定数 $\left(\mathrm{hPa} \cdot{ }^{\circ} \mathrm{C}^{-1}\right)$,

$R_{n}:$ 純放射量 $\left(\mathrm{MJ} \cdot \mathrm{m}^{-2} \cdot \mathrm{d}^{-1}\right)$,

$u_{2}:$ 地上高さ $2 \mathrm{~m}$ の風速 $\left(\mathrm{m} \cdot \mathrm{s}^{-1}\right)$,

$f\left(u_{2}\right)$ : 風速関数 $\left(\mathrm{mm} \cdot \mathrm{d}^{-1} \cdot \mathrm{hPa}^{-1}\right)(=026 \mathrm{x}$

$\left.\left(1+0.537 \cdot u_{2}\right)\right)$,

$e_{a}:$ 水蒸気圧 $(\mathrm{hPa}), e_{s a}$ : 飽和水蒸気圧 $(\mathrm{hPa})$ 
表- 1 推定式の比較

Table 1 Comparison of pan evaporation equations

\begin{tabular}{lcccc}
\hline & Penman eq. & Thornthwaite eq. & Hamon eq. & Hargreaves eq. \\
\cline { 2 - 5 } Correlation & $0.96 \pm 0.04$ & $0.77 \pm 0.15[16]$ & $0.79 \pm 0.13[1]$ & $0.86 \pm 0.11[126]$ \\
coefficient $(r)$ & $0.58 \pm 0.23$ & $1.38 \pm 0.32[4]$ & $1.22 \pm 0.32[6]$ & $0.83 \pm 0.43[133]$ \\
$R M S E(\mathrm{~mm})$ & $0.5 v$. S.
\end{tabular}

The brackets show the number of best fit among the three equations out of 143 station data.

O Evaporation $\Delta$ Pen eq $-\mathrm{TW}$ eq-- $\mathrm{Hm}$ eq $-\mathrm{Hr}$ eq

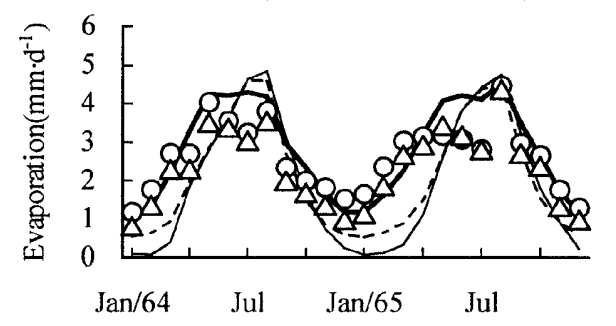

図 - 1 推定式による蒸発量 (宇都宮)

Fig. 1 Estimated evaporation at Utsunomiya by four pan evaporation equations

推定結果の一例を図-1に, 全国143地点の推定 結果のまとめを表-1に示す . 図 - 1から , Tw 式 , $\mathrm{Hm}$ 式の推定値が 8 月をピークとして単調な増加 · 減少を繰り返すのに対して, Hr 式の推定値は小型蒸 発計蒸発量の変動に連動する傾向が認められる . こ の傾向はほとんどの地点において共通して見られる . また表 - 1 は, 相関係数を基準にすると $\mathrm{Hr}$ 式によ る推定が143地点中126地点, 同じく RMSE では133 地点において最良となることを示し, $\mathrm{Hr}$ 式が他の 2 式 ( Tw 式, Hm 式) より優位であることが確認でき る.

これらの結果は, $\mathrm{Hr}$ 式が比較的高い適合性および 有効性をもつことを示しており，これは日射量を推 定する項の存在によるところが大きいと考えられる .

しかし一方で, $\mathrm{Hr}$ 式とペンマン式による推定值を 比べると, 変動に対する応答が鈍いことは明らかで あり, 温度のみを入力とする推定式の限界を示唆し ていると考えられる。

IV . ハーグリーヴス式の定数の検討

1 . 地域定数 $k_{R S}$

III. では地域定数 $k 0_{R S}$ を一律に0 17としたが， Hargreaves et al. (1985), Allen et al. (1998) が述べ ているように, 地域定数は地理的条件を反映するも

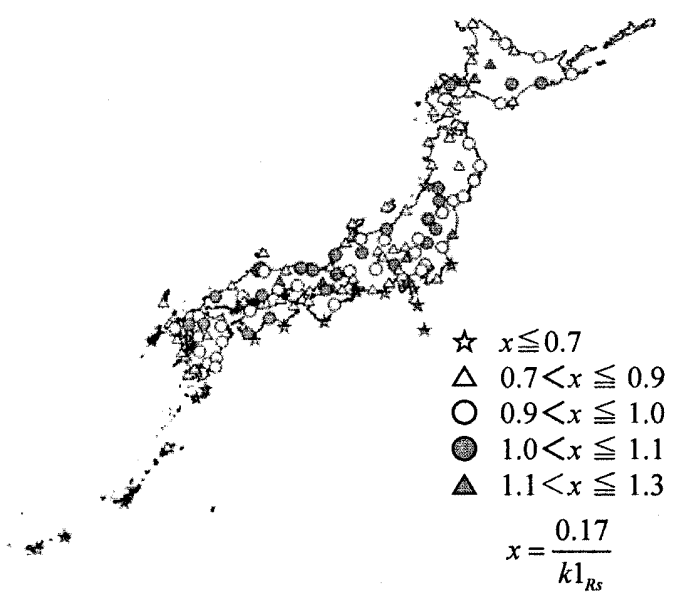

图 - 2 全国の地域定数

Fig. 2 Distribution of regional coefficient throughout Japan

のであり，一律に固定されるものではない．㫕こで， 蒸発量の実測值を目的変数, (3)式右辺の地域定数を 除いた項を説明変数, 定数項を 0 として, 最小自乗 法により各気象官署の地域定数 $k 1_{R s}$ を求めた . 求め

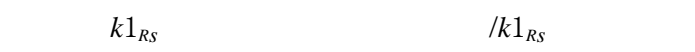
布を図 - 2 に示す. 図-2から, 臨海部・島嶼部で は比が1.0を下回る (蒸発量は過小評価される) 官 署が多く, 内陸部では周辺の臨海部・島嶼部より大 きい值を示す傾向があることがわかる.しかし，こ うして求められた地域定数は各気象官署固有の值で あり, 周辺に気象官署がない地域での蒸発量推定に は供することができない .この問題に対処するため には, 推定精度は低下しても, 地域定数は一律の值 あるいは何らかの式により一意に定められることが 望まれる . 前述したように地域定数は内陸部・臨海 部といった地理的条件との関係が窺われることから， 海岸からの距離を変数とした回帰式を導くことが適 当と考えられる。

乥こで, Hr 式を構成する全天日射量の推定式 


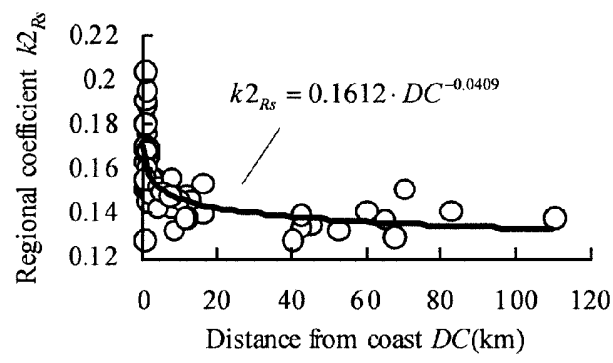

(a) Relationship between regional coefficients and

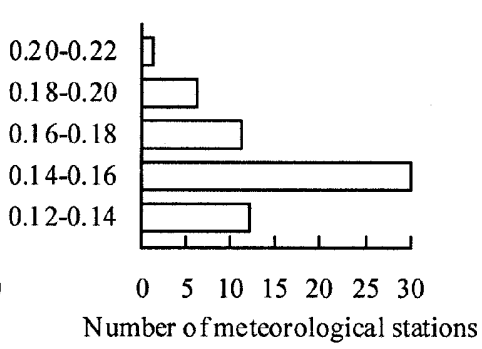

(b) Histogram of regional coefficient distance from coast

\section{图 - 4 地域定数}

Fig. 4 Regional coefficients

$$
R_{s}=k 2_{R s} \sqrt{T_{\max }-T_{\min }} R_{a}
$$

$k 2_{R S}:$ 地域定数

を対象として，地域定数の検討を行った . 具体的に は1986年〜2000年の15年間に67地点の気象官署で観 測された月別全天日射量を検証データとし，地域定 数 $k 2_{R S}$ を求めた .こうして求められた結果の一例を 図ー3に , 兴のまとめを表- 2 に示す. 表- 2 から 多くの地点で全天日射量が良好に推定されているこ とが分かる.しかし弚の一方で, 決定係数が 5を 下回る地点も 4 地点 (名瀬, 宮古島, 那覇, 南大東 島) ある .この 4 地点は南西諸島に位置しているこ

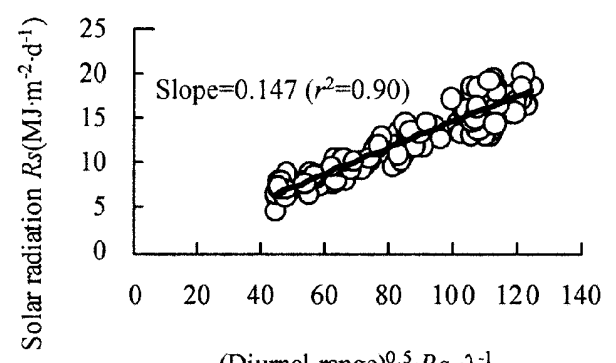

(Diurnal range) $)^{0.5} \cdot \operatorname{Ra} \cdot \lambda^{-1}$

図 - 3 地域定数の算出 (大阪)

Fig. 3 Determination of regional coefficient at Osaka

\section{表 - 2 地域定数の推定}

Table 2 Result of estimation of regional coefficient

\begin{tabular}{lccccccc}
\hline $\begin{array}{l}\text { Determination } \\
\text { coefficient }\left(r^{2}\right)\end{array}$ & $\sim 0.5$ & $\sim 0.6$ & $\sim 0.7$ & $\sim 0.8$ & $\sim 0.9$ & $\sim 1.0$ \\
\hline $\begin{array}{l}\text { Number of } \\
\text { stations }\end{array}$ & 4 & 0 & 5 & 12 & 25 & 21 \\
\hline Ave.: 0.86, S.D.: 0.07 & & & & &
\end{tabular}

とから，南西諸島に対しては(9)式，ひいては $\mathrm{Hr}$ 式 の適用に限界があることを示唆している .これは Allen et al. (1998) の指摘，つまり島嶼部では海の 影響で日較差が小さいため(9)式の適合性に限界があ るという内容と共通しており，本稿では南西諸島 (具体的には地点番号47901以降の気象官署) につい ては全天日射量および蒸発量推定の対象外とした . なお，この他の島嶼部 (例えば, 大島，厳原) では 先の 4 地点ほど推定精度が低くなかったため (大島 $r^{2}=0.761$, 厳原 $\left.r^{2}=0.746\right)$ ため, 対象外とはしな かった .

こうして求められた地域定数 $k 2_{R S}$ と海岸からの距 離 $D C(\mathrm{~km})$ の関係を図 - 4 に示す.この両者の回 帰式は

$$
k 2_{R s}=0.612 \cdot D C^{-0.0409} \quad\left(r^{2}=0.48\right)
$$

と求められた . 以降, 本稿では地域定数の算出には (10)式 , 全天日射量の推定には(10)式を(9)式に代入した ものを用いた .

また図－4(b)から，一般的な $\mathrm{Hr}$ 式 ((4)式) を小 型蒸発計蒸発量の推定に用いると, 地域定数 $k 0_{R S}$ の 值0 17はわが国では若干大きめの值となることが推 測された .

\section{2 . 経験定数 $\varepsilon$}

経験定数 $€$ は , (3)式を整理すると

$$
\epsilon=\frac{E T_{0}}{32+1.8 \cdot T_{\text {mean }}} \cdot \frac{\lambda}{R_{s}}
$$

と表され，月毎に算出することができる．

$\mathrm{Hr}$ 式は全天日射量と気温の関数から構成され， 既に気温の項が含まれているが，ここでは重ねて経 験定数と月平均気温 $T_{\text {mean }}$ との関係について検討し た。 


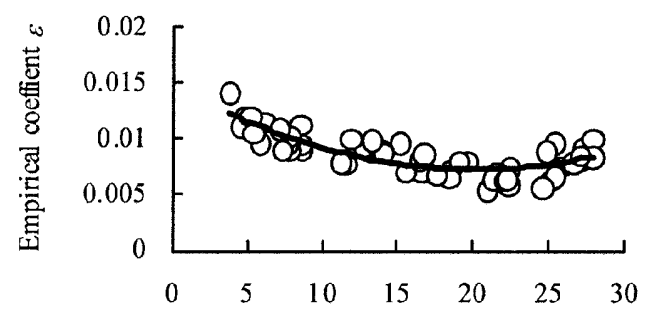

Monthly mean temperature $T_{\text {mean }}\left({ }^{\circ} \mathrm{C}\right)$

図 - 5 月平均気温と経験定数 $\epsilon$ (横浜)

Fig. 5 Monthly mean temperature and empirical coefficient $\epsilon$ at Yokohama

\section{表 - 3 経験定数の推定}

Table 3 Result of estimation of empirical coefficient

\begin{tabular}{lcccccc}
\hline $\begin{array}{l}\text { Determination } \\
\text { coefficient }\left(r^{2}\right)\end{array}$ & $\sim 0.2$ & $\sim 0.4$ & $\sim 0.6$ & $\sim 0.8$ & $\sim 1.0$ \\
\hline $\begin{array}{l}\text { Number of } \\
\text { stations }\end{array}$ & 14 & 20 & 51 & 37 & 16 \\
\hline Ave.: 0.52, S.D.: & 0.22 & & & &
\end{tabular}

表 - 4 経験定数の近似式の定数項と地理的条件の 相関

Table 4 Correlation coefficient of constants in the approximation of empirical coefficient and the geographic condition

\begin{tabular}{lccc}
\hline & $a_{j}$ & $b_{j}$ & $c_{j}$ \\
\cline { 2 - 4 } Latitude $\left(\mathrm{N}^{\circ}\right)$ & 0.11 & -0.03 & -0.18 \\
Altitude $(\mathrm{m})$ & 0.05 & -0.15 & 0.22 \\
Distance & -0.02 & -0.09 & 0.07 \\
from coast $(\mathrm{km})$ & - & & \\
\hline
\end{tabular}

結果の一例として, 横浜における経験定数と月平 均気温 $T_{\text {mean }}$ の関係を図 - 5 に示す. 図 -5 に見ら れるように, 経験定数は月平均気温 $T_{\text {mean }}$ の二次式

$$
\epsilon_{j}=a_{j}\left(T_{\text {mean }}-b_{j}\right)^{2}+c_{j}
$$

$$
a_{j}, b_{j}, c_{j} \text { : 定数 }(j: \text { 観測地点 })
$$

により比較的良好に近似できる.結果的に，全天日 射量に掛ける值は月平均気温 $T_{\text {mean }}$ の三次式により 与えられることとなる.こうして求められた全国 (南西諸島を除く) 138地点における近似式の決定係 数のまとめを表-3に示す. 表-3が示すように ， 地点毎に近似式を求めると比較的良好な結果が得ら れる.しかし, 蒸発量の観測を行っていなかった地 点・地域で推定を行うためには，(12)式の定数が一意 に定まることが望ましい，乥こで，(12)式の各定数と

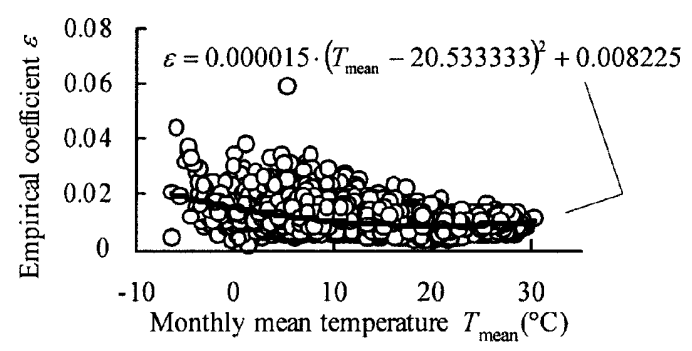

図 - 6 月平均気温と経験定数 $\epsilon$ (全国)

Fig. 6 Monthly mean temperature and empirical coefficient $\epsilon$ throughout Japan

緯度 , 標高 , 海岸からの距離との関係を検討したが， 有意な関係は認められなかった (表 -4$)$. 弚のた め, 全地点の全データ (7630個) を対象として改め て近似曲線を求め(図-6), (13)式を得た.

$\epsilon=0.000015 \cdot\left(T_{\text {mean }}-20.533333\right)^{2}+0.008225$ (13)

$$
\left(r^{2}=028\right)
$$

(13)式の決定係数 $r^{2}$ は0 28と決して良いとは言い難 いが , 全国共通の近似式を得るという趣旨からやむ を得ないものと考えた .

地域定数と同樣に，一般的な $\mathrm{Hr}$ 式との比較では， (13)式で, $a$ が0 $.000015(>0), c$ が0 0.008225 となるこ とから，わが国においては(3)式の経験定数0.0075が 幾分小さめの值であることが推測される .このこと と，IV.1.で指摘した一般的な地域定数0 17が若 干大きめの值であることを考え合わせると，一般的 な $\mathrm{Hr}$ 式では $2 つ の$ 定数が掛け合わされることによ り，両者の大小が相殺されているものと推測される . なお，一般的な $\mathrm{Hr}$ 式の経験定数が定数であるの に対し，(13)式により求められる経験定数は月平均気 温 $T_{\text {mean }}$ の二次式となっている .これは , 観測機器 の差異 (ライシメータ, 蒸発計) が一因になってい ると思われるが, 比較対照となるライシメータの データが整備されていないため, 本稿では考察を行 わなかった . また , 大型蒸発計蒸発量に移行する 1966年以降への(13)式の適合性についても，小型蒸発 計と大型蒸発計の観測データを同質のデータとして 扱うことが難しいことから，今後の課題とした .

3 . 修正ハーグリーヴス式による推定 (10)式，(13)式を(3)式に代入し , Hr 式を

$$
\begin{aligned}
E_{H r}= & \epsilon\left(32+18 \cdot T_{\text {mean }}\right) k 2_{R s} \sqrt{T_{\max }-T_{\min } R_{a}} \\
= & \left(0.000015 \cdot\left(T_{\text {mean }}-20.533333\right)^{2}+0.008225\right)(14) \\
& \times\left(32+18 T_{\text {mean }}\right)
\end{aligned}
$$




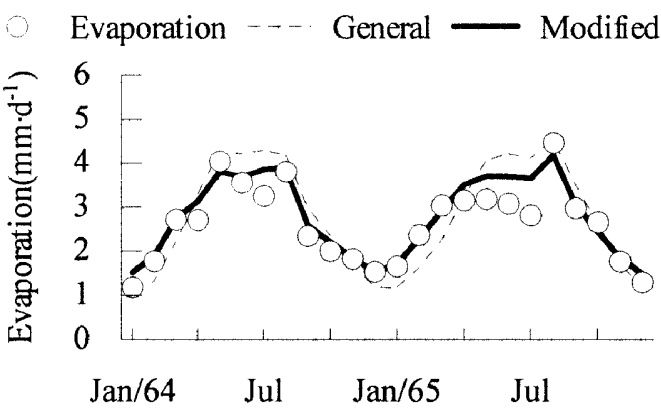

図 - 7 修正 Hargreaves 式による蒸発量 (宇都宮)

Fig. 7 Estimated evaporation by general Hargreaves equation and modified one at Utsunomiya

表 - 5 従来式と修正式の比較

Table 5 Comparison between results by the general and modified Hargreaves equations

\begin{tabular}{lccc}
\hline & Penman & general & modified \\
\cline { 2 - 4 } Correlation & $0.96 \pm 0.04$ & $0.86 \pm 0.11$ & $0.89 \pm 0.10$ \\
coefficient $(r)$ & $0.58 \pm 0.22$ & $0.78 \pm 0.34$ & $0.65 \pm 0.26$ \\
\hline$R M S E(\mathrm{~mm})$ & $0 . \mathrm{S} . \mathrm{D}$.
\end{tabular}

$\times\left(01612 D C^{-0.0409}\right) \quad \sqrt{T_{\max }-T_{\min }} \frac{R_{a}}{\lambda}$

$E_{H r}: \mathrm{Hr}$ 式による蒸発量 $\left(\mathrm{mm} \cdot \mathrm{d}^{-1}\right)$

として, 改めて全国138地点（南西諸島を除く）の 小型蒸発計蒸発量の推定を行った . 谷の計算結果の 一例を図-7に，一般的な $\mathrm{Hr}$ 式との比較を表 -5 に示す.相関係数は0 86から0 89, RMSE では $0.78 \mathrm{~mm}$ から $.65 \mathrm{~mm}, R M S E$ の標準偏差も0 34から 026 と推定精度が向上している.また, ペンマン式 との比較でも, 相関係数は依然として差があるもの の，RMSE の差はO $.07 \mathrm{~mm}$ となり，精度の向上が認 められる .

以上の結果は, 地域定数, 経験定数に関する検討, 修正が有効であったことを示していると思われる．

$\mathrm{V}$.まとめ

わが国へのハーグリーヴス式の適用およびパラ メータとなる定数項の検討を行い, 以下の結果を得
た.

(1) 気温のみを入力して蒸発量を推定するソーンス ウェイト式 , ハモン式 , ハーグリーヴス式の 3 式 を比較すると，ハーグリーヴス式の適合性が高い．

(2) 日較差から全天日射量を推定する式の定数 (地 域定数) は, 海岸からの距離を変数とする累乗関 数で一意に定めることができる．また, 南西諸島 についてはハーグリーヴス式の適用が困難である .

(3) 全天日射量と平均気温 $T_{\text {mean }}$ の積から蒸発量を 求める定数 (経験定数) は, 平均気温 $T_{\text {mean }}$ の二 次式で一意に定めることができる .

(4) 導出した定数の推定式を使うことにより，従来 のハーグリーヴス式より精度よく小型蒸発計蒸発 量の推定が可能である .

謝辞 : 本研究にあたり，宇都宮大学農学部石田朋靖 教授には折にふれ有益な助言を頂いた .ここに記し て深謝する。

\section{引用文献}

Allen, R. G., Pereira, L. S., Raes, D., and Smith, M. (1998) : Crop Evapotranspiration. FAO Irrigation and Drainage Paper, 56, pp. 60-64.

Jensen, M. E. and Haise, H. R. (1963) : Estimating Evapotranspiration From Solar Radiation. J. Irri. and Drain. Div., ASCE, 89 (IR4) , 15-41.

Hargreaves, G. H. and Samani, Z. A. (1982): Estimating Potential Evapotranspiration. J. Irri. and Drain. Div., ASCE, 108 (IR3) , pp. 225-230.

Hargreaves, G. H. and Samani, Z. A. (1985) : Reference Crop Evapotranspiration from Temperature. Appl. Eng. Agric, 1 (2) , pp. 96-99.

Makkink, G. F. (1957) : Ekzameno de la Formulo de Penman. J. Agric. Sci., 5, 290-305.

Priestley, C. H. B. and Taylor, R. J. (1972) : On the Assessment of Surface Heat Flux and Evaporation using Large-scale Parameters. Mon. Weather Rev., 100, pp. 81-92.

(受付 : 2002年11月12日, 受理 : 2003年 4 月12日) 